\title{
Epidemiological and clinical features, response to HAART, and survival in HIV-infected patients diagnosed at the age of 50 or more MaMercedes Nogueras*1, Gemma Navarro ${ }^{1}$, Esperança Antón1, Montserrat Sala ${ }^{1}$, Manel Cervantes ${ }^{1}$, MaJosé Amengual ${ }^{2}$ and Ferran Segura ${ }^{1}$
}

\author{
Address: ${ }^{1}$ Infectious Diseases Program, Corporació Sanitària Parc Taulí, Sabadell, Barcelona, Spain and 2UDIAT Diagnosis Centre, Corporació \\ Sanitària Parc Taulí, Sabadell, Barcelona, Spain \\ Email: MaMercedes Nogueras* - mnogueras@cspt.es; Gemma Navarro - gnavarro@cspt.es; Esperança Antón - eanton@cspt.es; \\ Montserrat Sala - msala@cspt.es; Manel Cervantes - mcervantes@cspt.es; MaJosé Amengual - mjamengual@cspt.es; \\ Ferran Segura - fsegura@cspt.es \\ * Corresponding author
}

Published: 06 November 2006

BMC Infectious Diseases 2006, 6:159 doi:10.1 186/147|-2334-6-159
Received: 28 July 2006

Accepted: 06 November 2006

This article is available from: http://www.biomedcentral.com//47I-2334/6/I59

(C) 2006 Nogueras et al; licensee BioMed Central Ltd.

This is an Open Access article distributed under the terms of the Creative Commons Attribution License (http://creativecommons.org/licenses/by/2.0), which permits unrestricted use, distribution, and reproduction in any medium, provided the original work is properly cited.

\begin{abstract}
Background: Over the last years, the mean age of subjects with HIV infection and AIDS is increasing. Moreover, some epidemiological and clinical differences between younger and older HIV-infected individuals have been observed. However, since introduction of HAART therapy, there are controversial results regarding their response to HAART. The aim of the present study is to evaluate epidemiological and clinical features, response to HAART, and survival in elderly HIVinfected patients with regard to younger HIV-infected patients.
\end{abstract}

Methods: A prospective cohort study (1998-2003) was performed on patients from Sabadell Hospital, in Northeast of Spain. The cohort includes newly attended HIV-infected patients since January I, 1998. For the purpose of this analysis, data was censured at December 3I, 2003. Taking into account age at time of diagnosis, it was considered $36 \mathrm{HIV}$-positive people aged 50 years or more (Group I, GI) and 4 I 9 HIV-positive people aged I 3-40 years (Group 2, G2). Epidemiological, clinical, biological and therapy data are recorded. Statistical analysis was performed using Chisquared test and Fisher exact test, Mann-Whitney $U$ test, Kaplan-Meier, Log Rank test, and TwoWay ANOVA from random factors.

Results: GI showed higher proportion of men than $G 2$. The most common risk factors in $G 1$ were heterosexual transmission $(P=0.0 \mathrm{I})$ and having sex with men or women $(P<0.00 \mathrm{I})$. GI and G2 show parallel profiles through the time regarding immunological response $(P=0.989)$ and virological response $(P=0.074)$. However, older people showed lower CD4 cell counts at first clinic visit $(P<0.00 \mathrm{I})$ and, eventually, they did not achieve the same counts as G2. GI presented faster progression to AIDS $(P<0.00 \mathrm{I})$ and shorter survival $(P<0.00 \mathrm{I})$.

Conclusion: Older patients have different epidemiological features. Their immunological and virological responses are good. However, older patients do not achieve the same CD4 cell counts likely due to they have lower counts at first clinic visit. Thus, it is essential physicians know older HIV-infected patients features to consider the possibility of HIV infection in these patients with the aim of treatment would not be delayed. 


\section{Background}

Over the last years, the proportion of old individuals infected with HIV is increasing. For instance, patients older than 50 years were more than $10 \%$ of AIDS notifications made in the last ten years in USA [1]. More than 90500 individuals over 50 years are living with AIDS in this country [2]. In Europe, $12.6 \%$ of AIDS patients were older than 50 years in 1998 , whereas $14.5 \%$ of them had more than 50 years in 2002 [3]. Since the beginning of the HIV pandemic to 2005, 71039 cases of AIDS have been reported in Spain. Mean age at time of diagnosis was 40.3 years [4].

The progressive increase of mean age of subjects with HIV infection and AIDS could be explained by different factors. Since 1996, when highly active antiretroviral therapy (HAART) was available, the history of HIV infection has evolved from acute or subacute disease to a chronic and controllable infection. Thus, HIV-infected people grow older and live longer. Antimicrobial therapy and chemoprophylaxis have also allowed the increase survival of people living with HIV infection. Moreover, some epidemiological features have changed. The importance of sexual transmission as mode of HIV spread is increasing [1]. Therefore, there are a number of patients who are not aware of their infection, delaying the diagnosis.

There are epidemiological differences between younger and older HIV-infected individuals. Older people have a higher prevalence of sexual HIV transmission, a reduction of transmission due to intravenous use, and a higher proportion of men $[5,6]$. On the other hand, there are controversial data about the virological and immunological responses to HAART as well as survival in older patients. Some studies indicates that the duration of survival is significantly shorter for elderly people due to deficiencies in the immune system related to age $[7,8]$. However, others studies seem to show older people have the same response to HAART than younger patients $[9,10]$.

In the past, there was little attention to older people with HIV infection due to the little number of them. Nevertheless, the importance of knowledge about the HIV infection in this population is increasing. The aim of the present study is to characterize the ways in which older HIV infected people differ from younger, in a Spanish cohort. Our previously hypothesis are: firstly, older patients have different epidemiological and clinical features; secondly, they response to HAART in the same way that younger patients. The survey takes into account epidemiological and clinical features, virological and immunological responses, prognostic, and survival.

\section{Methods \\ Study setting}

Subjects were enrolled at the Sabadell Hospital. This is a 765-bed general teaching hospital located in Barcelona, Spain. It provides primary and specialty care for HIV infection to 850 patients, approximately.

\section{Design}

A prospective cohort study (1998-2003)

\section{Database}

Eligible patients were enrolled at the PISCIS project. The latter is a multicenter cohort (10 hospitals of Catalonia and one from Balearic Islands) of HIV-infected people whose features are entered into a computerized database [11]. Inclusion criteria are: to be more than 16 years old, to have confirmed positive serology against HIV, and to be attended at first time from January 1, 1998 in one hospital of the study. All patients with these conditions are included in PISCIS cohort independently of AIDS criteria. Characteristics at first clinic visit are recorded for all patients by clinicians. Epidemiological, clinical, biological and antiretroviral therapy data are sent to the Coordination Centre every four months. Patients' names were codified to attain anonymity. The project was conducted under the terms of Ethics committee approval from Sabadell Hospital.

\section{Study population}

Five hundreds twelve subjects from Sabadell's Hospital included in the PISCIS project were analyzed. They were enrolled between January 1, 1998, and December 31, 2003. Two groups were defined taking into account the age at the time of diagnosis. Patients were included in two age groups. Group 1 (G1) consisted of HIV-infected people 50 years or older $(n=36)$, whereas Group 2 (G2) consisted of patients aged $13-40$ years $(n=419)$. Like other studies $[9,10,12-15]]$, patients aged between G1 and G2 groups $(n=57)$ were excluded in order to separate both groups. It was decided that the cut off would be 50 years old considering many previously HIV-infection studies data as well as most significant immunological change take place around this age.

\section{Parameters evaluated}

For each subject enrolled, the following data were obtained: age, gender, HIV-risk behavior, data of the first available HIV test, CDC stage of HIV infection, date of AIDS diagnosis, number of visits, cause of visit, number of hospitalizations after HIV diagnosis, antiretroviral therapy, AIDS-defining diseases, and data of death. Data collected from laboratory were: number of CD4+ and CD8+ T cells, and HIV RNA viral load with a limit of detection below 200 copies/ml. Subjects underwent periodical clinical evaluations including laboratory determinations. 
AIDS criteria were established by Centers for Disease Control and Prevention (CDC), category C.

\section{Statistical analysis}

Software program SPSS 11.5 (SPSS Inc, Chicago IL) was used.

Group comparisons were performed using Chi-squared test. However, if a cell of the table had few expected cases $(<5)$, Fisher exact test was used.

In baseline characteristics analysis, P-values were adjusted by Bonferroni procedure in order to control the familywise Type I error-rate because thirteen simultaneous hypotheses were tested.

All continuous variables were compared by Mann-Whitney $U$ test because their distributions were not normal.

Kaplan-Meier and Log Rank test were used to estimate and to compare survival functions between two groups.

The mean increase in the CD4 cell count and the mean decrease in viral load over time were studied using a mixed ANOVA procedure. Two-Way ANOVA from random factors were used where age group, and time were fixed factors, and patient was random factor. This model studies effect of age, time and interaction between age and time, on CD4 cell count or viral load. Residuals independency and normality were verified.

Patients were recorded as alive at their last visit. A P $<0.05$ was considered significant.

\section{Results \\ Study population}

A total of 512, who were newly attended in our hospital since January 1, 1998, to December 31, 2003, were analyzed. They have been diagnosed of HIV-infection since 1983 to 2003. The mean age of HIV patients at first diagnosis is progressively rising: $23.34 \pm 4.33$ years $(14-33$ years) at $1983-1988$ period, $26.32 \pm 4.73$ years $(16-36$ years) at $1989-1993$ period, $31.45 \pm 9.04$ years $(15-69$ years) at $1994-1998$ period, and $37.27 \pm 14.25$ years ( 17 - 82 years) at 1999 - 2003 period. There were no HIVinfected people being 50 years or older at the time of diagnosis until 1996, when the first old patient was enrolled (Fig 1).

\section{Characteristics at first clinic visit}

A total of 36 subjects belonged to G1 (7.9 \%) and 419 individuals to G2 $(92.1 \%)$. Their characteristics at first clinic visit are shown (Table 1). The mean age was 62.44 \pm 9.57 years ( $50-82$ years) for the older group and 28.29 \pm 6.15 years ( $14-40$ years) for the younger group. Older group showed higher proportion of men than younger group.

The most common risk behavior for the acquisition of HIV infection in G1 was sexual contact, whereas injection drug use was the most important risk factor in G2. Moreover, there were a greater percentage of older patients whose risk behavior is unknown.

At the enrollment, there was no statistically significant difference between both groups with regard to the AIDS criteria. However, time from diagnosis of HIV to enrollment was lower in elderly group $(P<0.001)$. In fact, seven patients from G1 presented AIDS criteria at the enrollment and their mean time since diagnosis of HIV was 6.57 \pm 11.93 days ( 0 - 30 days). Fifty patients from G2 were enrolled with AIDS criteria and their mean time since diagnosis of HIV was $2273.72 \pm 2217.03$ days $(0-7376$ days).

In the younger group, there were more individuals with previous treatment than in older group $(P<0.001)$.

At first clinic visit, elderly group had a lower mean CD4 cells count $\left[180.83 \pm 230.85(5-1309)\right.$ cells $/ \mathrm{mm}^{3}$ versus $366.89 \pm 294.52(2-1819)$ cells $\left./ \mathrm{mm}^{3},\right]$, and a higher viral load $\left[4.51 \pm 1.18(2.3-5.88) \log _{10}\right.$ copies/mL versus 4.05 $\pm 1.22(1.59-5.97) \log _{10}$ copies $\left./ \mathrm{mL}\right]$. There were not differences relating to CD8 cells count.

There was higher percentage of younger people who had antibodies against hepatitis $C$ virus $(P<0.001)$.

Elderly group had higher number of patients who were admitted to the hospital (47.2\% versus $30.1 \%, P=$ 0.032 ). Most elderly patients were admitted to the hospital because of Pneumocystis jiroveci infection (41.2\%), tuberculosis (11.8\%), Herpes zoster infection (5.9\%), and Kaposi's sarcoma $(5.9 \%)$. On the other hand, young patients were admitted to the hospital because of widely conditions as Pneumocystis jiroveci infection (12\%), tuberculosis $(9.6 \%)$, bacterial pneumonia $(8 \%)$, hepatic diseases, renal diseases, cardiovascular diseases, encephalopathy, or different kind of infectious diseases.

\section{Treatment}

At the enrollment, there was more percentage of younger patients who received previous treatment. Nevertheless, most patients from both age groups were treated during follow-up. In fact, $31(86.1 \%)$ of individuals being 50 years or older and $338(80.7 \%)$ of individuals aged 1340 years received at least one antiretroviral drug for some time during follow-up. Number of patients from G1 and G2 who were receiving treatment at one, two, three, and four years of follow-up were $23 / 23$ (100\%) versus $148 /$ 


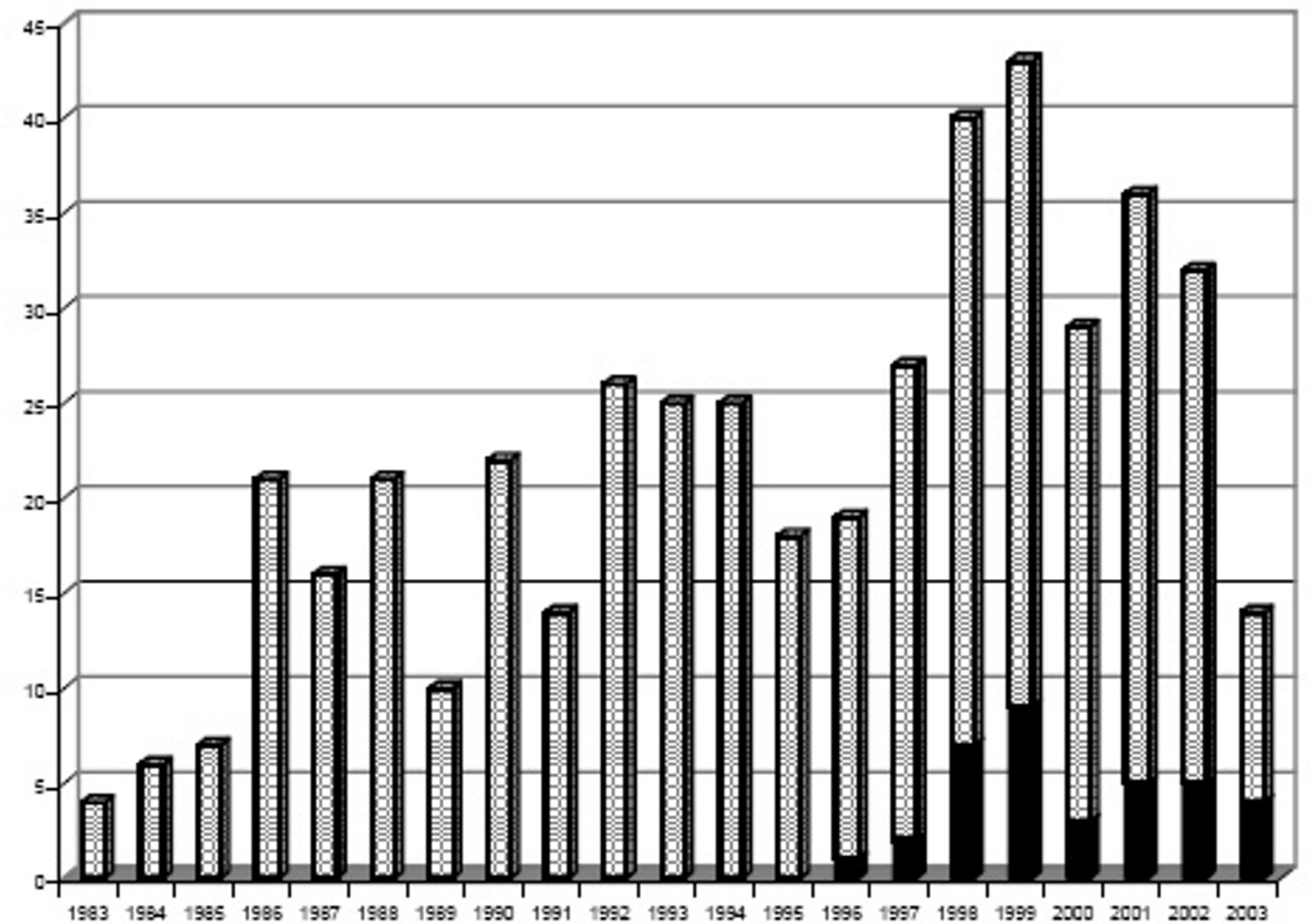

$\mathrm{G} 1: 250$ years

G2: $13-40$ years

Figure I

Evolution of HIV diagnosed cases considering age groups.

$164(90.2 \%), 17 / 17$ (100\%) versus $111 / 119$ (93.3\%), 13/ $13(100 \%)$ versus $71 / 75(94.7 \%)$, and $8 / 8$ (100\%) versus $46 / 50$ (92\%), respectively. There were no statistically significant differences between groups at any point of time.

Whereas there was no difference in the use of antiretroviral, the mean time between HIV diagnosis and therapy initiation is lower in elderly group [3.48 $\pm 6.35(0-24.01)$ months versus $73.11 \pm 64.15(0-240.13)$ months]. Most of patients received three antiretrovirals (70.9\% in G1 and $61.6 \%$ in G2).

\section{Immune and virological responses}

CD4 cell counts and viral load were obtained every six months during the follow-up since first visit. Figure 2 shows the mean data from CD4 cell counts and viral load according to time and age group. The mixed ANOVA procedure was carried out in order to study if both age groups showed similar virological and immunological responses.

Patients from G1 had higher viral load and lower CD4 cell count at the enrollment. In both groups, greatest immune and virological responses were observed in the first six month. However, these patients did not achieve the same CD4 cell counts than younger individuals.

Considering increase of CD4+ cell number, both age group showed parallel profiles (age group $\times$ time: $P=$ $0.989)$. Statistically significant increase through the time was observed in both groups (time: $P=0.005$ ). Younger patients had higher number of CD4+ cells during followup (age group: $P<0.001$ ). 
Table I: Characteristics of the Sample and its Subgroups at first clinic visit

\begin{tabular}{|c|c|c|c|c|}
\hline Characteristic & Total Sample & Group I (GI) & Group 2 (G2) & $P$-value $\mathbb{\Upsilon}$ \\
\hline Sample size $(n)$ & 455 & 36 & 419 & \\
\hline \multicolumn{5}{|l|}{ Sex: n (\%) } \\
\hline Male & $334(73.4)$ & $33(91.7)$ & $301(7 I .8)$ & 0.127 \\
\hline Female & $|2|(26.6)$ & $3(8.3)$ & I I 8 (28.2) & \\
\hline \multicolumn{5}{|l|}{ HIV risk factor: $\mathrm{n}(\%)$} \\
\hline IDU * & $285(62.9)$ & $2(5.7)$ & $283(67.7)$ & $<0.001$ \\
\hline Heterosexual & $123(27)$ & $16(44.4)$ & $107(25.5)$ & 0.132 \\
\hline MSM ** & $23(5.1)$ & $4(11.1)$ & $19(4.5)$ & $<0.999 \|$ \\
\hline MSMW $\ddagger$ & $8(1.8)$ & $6(16.7)$ & $2(0.5)$ & $<0.001 \|$ \\
\hline Unknown & $16(3.5)$ & $8(22.2)$ & $8(2)$ & $<0.001 \|$ \\
\hline \multicolumn{5}{|l|}{ AIDS criteria: $n(\%)$} \\
\hline Yes $\S$ & $57(12.5)$ & $7(19.4)$ & $50(11.9)$ & $<0.999 \|$ \\
\hline No & $398(87.5)$ & $29(80.6)$ & $369(88.1)$ & \\
\hline \multicolumn{5}{|l|}{ Previous treatment: $\mathrm{n}(\%)$} \\
\hline Yes & $181(39.8)$ & $2(5.6)$ & $179(42.7)$ & $<0.001$ \\
\hline No & $274(60.2)$ & $34(94.4)$ & $240(57.3)$ & \\
\hline CD4 $\left(n^{\circ}\right.$ cel. $\left./ \mathrm{mm}^{3}\right)$ & $352.08 \pm 294.10$ & $180.83 \pm 230.85$ & $366.90 \pm 294.52$ & $<0.001$ \\
\hline CD8 $\left(\mathrm{n}^{\circ} \mathrm{cel} . / \mathrm{mm}^{3}\right)$ & $957.82 \pm 597.10$ & $963.38 \pm 733.22$ & $956.97 \pm 583.73$ & $<0.999$ \\
\hline Plasma viral load $(\log 10)$ & $4.09 \pm 1.22$ & $4.51 \pm 1.18$ & $4.05 \pm 1.22$ & $0.45 I$ \\
\hline \multicolumn{5}{|l|}{ HBsAg \#: n (\%) } \\
\hline Positive & $24(8.1)$ & I (4.5) & $23(8.3)$ & $<0.999$ \\
\hline Negative & $274(91.9)$ & $21(95.5)$ & 253 (91.7) & \\
\hline \multicolumn{5}{|l|}{ Anti-HCV: n (\%) } \\
\hline Positive & $197(56.8)$ & $3(13.6)$ & $194(65.1)$ & $<0.001$ \\
\hline Negative & $123(43.2)$ & $19(86.4)$ & $104(34.9)$ & \\
\hline
\end{tabular}

II $P$ value adjusted by Bonferroni procedure; * IDU: Injection drug user; ** MSM: Men who have sex with men; || Fisher exact test; $\ddagger$ MSMW: Men who have sex with men or women; $\S$ AIDS criteria: Centers for Disease Control and Prevention (CDC) category C; \# HBsAg: Hepatitis B superficial antigen

Taking into account decrease in plasma viral load, both age groups show not different behavior (age group $\times$ time: $P=0.074)$. A statistically significant decrease through the time was observed in both groups (time: $P<0.001$ ), and older patients had lower viral load (age group: $P=0.013$ ), since 6 months of follow-up.

\section{Clinical progression}

Even if there were no significant difference regarding AIDS criteria at the enrollment, greater number of older patients developed AIDS. Of patients without AIDS criteria at enrollment, percentage of cases and mean time of progression to first AIDS event were calculated. In fact, 18 (50\%) cases occurred in G1, and $121(28.87 \%)$ in G2 $(P=$ 0.006) during follow-up. Compared by Log Rank test, G1 progression to AIDS was higher than G2 $(P<0.001)$. In a Kaplan-Meier analysis, mean times of progression to AIDS were $57.72 \pm 8.91(40.26-75.18)$ months in G1 and $180.04 \pm 5.10(170.05-190.03)$ months in G2. Younger HIV-infected people had a probability of remaining AIDSfree of $96.36 \%$ and $94.32 \%$ at one and two years of HIV diagnosis, respectively. However, older individuals' probabilities were $62.96 \%$ and $58.77 \%$ at the same moments.
The most common AIDS-defining diseases are Pneumocystis jiroveci infection ( $25 \%$ vs. $9.3 \%$ ), tuberculosis ( 8.3 $\%$ vs. $14.31 \%$ ), Kaposi's sarcoma ( $5.5 \%$ vs. $0.23 \%$ ), Candidiasis (5.5\% vs. $2.38 \%$ ), Cytomegalovirus infection (2.7 $\%$ vs. $0.47 \%$ ), caquexia ( $2.7 \%$ vs. $0.23 \%$ ), Herpes simple infection (2.7 \% vs. $0.23 \%)$, and encephalopathy ( $2.7 \%$ vs. $1.19 \%)$. There are significant statistically differences regarding Pneumocystis jiroveci infection $(P=0.008)$ and Kaposi's sarcoma $(P=0.017)$. There were no differences between both groups with regard to time since HIV diagnosis to Pneumocystis jiroveci infection. There was no statistical difference between age groups with reference to number of tuberculosis cases. In a Kaplan-Meier analysis, time of progression to tuberculosis was $6.29 \pm 0.53$ (5.24 - 7.33) in G1 and $16.05 \pm 0.42(15.23-16.86)$ months (Log Rank test, $P=0.037$ ). Patients developed one (82.6 $\%)$, two $(16.7 \%)$ or three $(0.7 \%)$ AIDS-defining diseases at same time. However, there was no significant difference between both age groups.

\section{Survival}

A total of $16(3.8 \%)$ patients aged $13-40$ years were exitus. In contrast, five (13.9\%) of HIV-infected patients 
CD4 (cel/mm3)

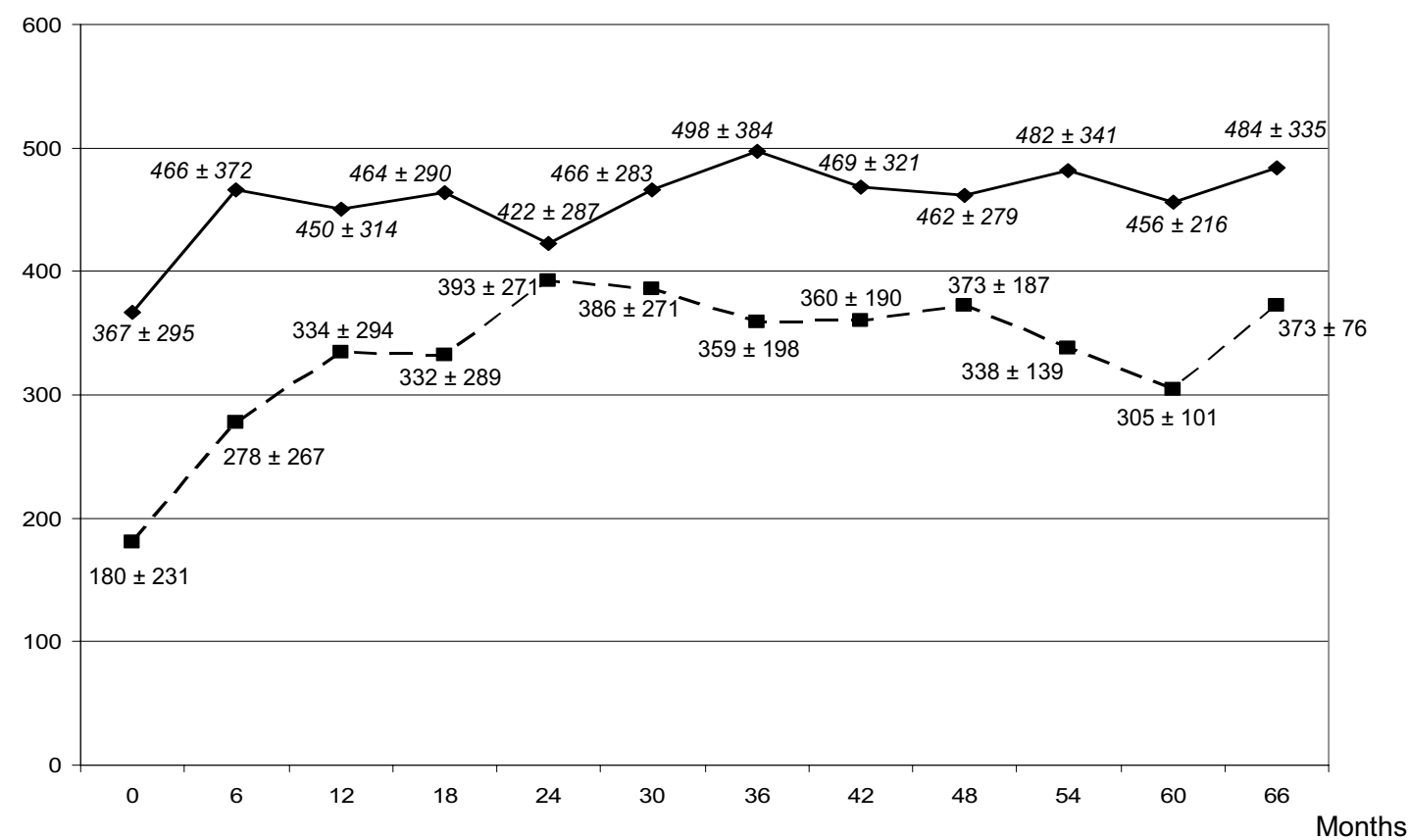

Plasma viral load $(\log 10)$

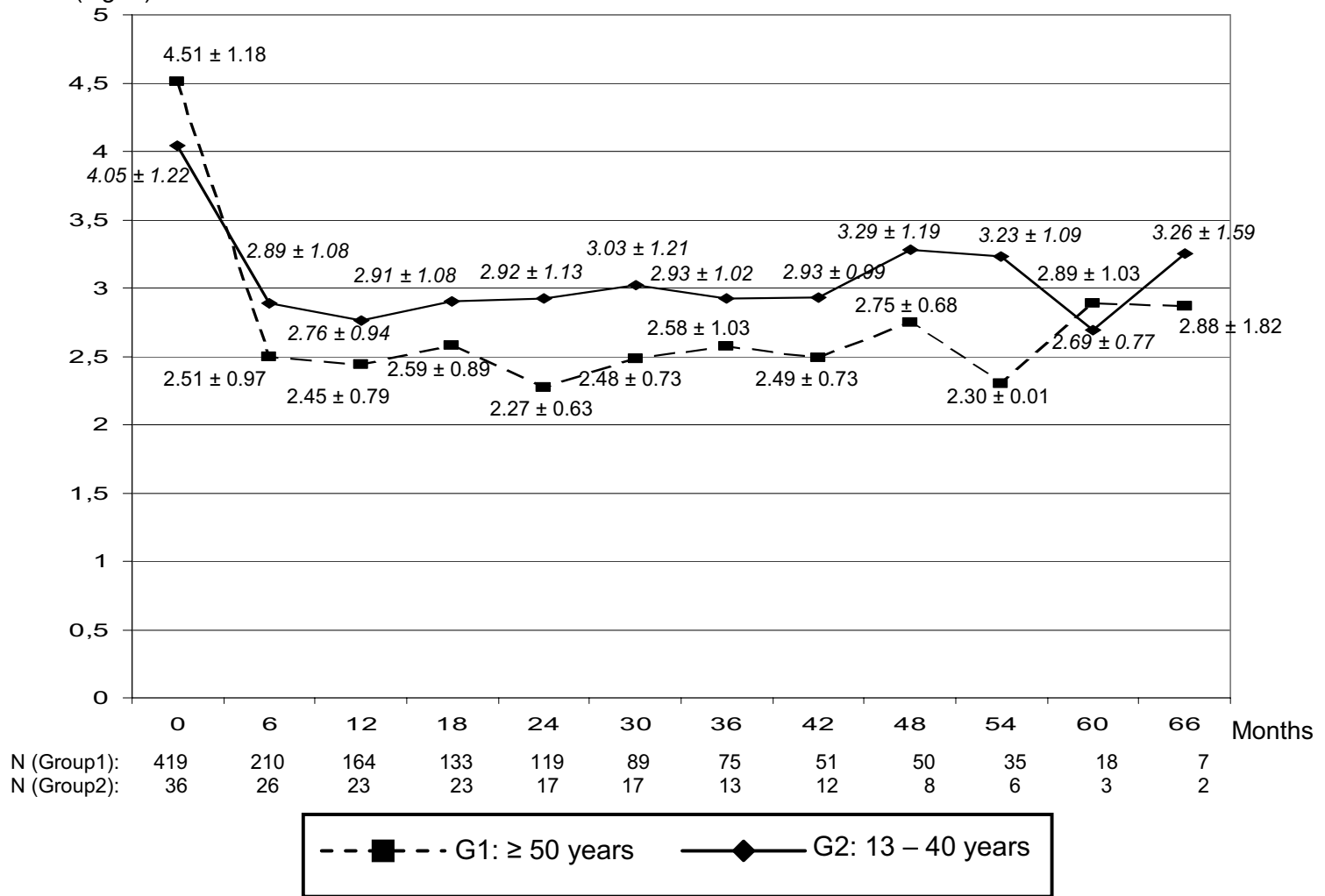

Figure 2

CD4 cell count and viral load (mean \pm SD) at first visit and each six months of follow-up. 
being 50 years or older died during the follow-up $(P=$ $0.019)$. Mean survival time was $2520.6 \pm 166.2$ (2194.8 2846.3) months in G1 and $7343.8 \pm 79.9$ (7186.9 7500.5) months in G2. In figure 3, Kaplan-Meier survival curves are showed. Log Rank test was statistically significant $(P<0.001)$. Every death in the older group occurred in the first year since HIV diagnosis. Cumulative proportions of younger patients who survived were $99.52 \%$ at one year, $98.28 \%$ at three years, and $97.40 \%$ at five years.

\section{Discussion}

Since 1996, when HAART became widely available, elderly patients infected with HIV are a growing population $[3,6]$. HAART is effective in increasing CD4 cell counts and in decreasing the virus load, so it has been associated with a $50 \%$ decrease in morbidity and mortality with AIDS. Therefore, HIV-infected individuals have prolonged survival and they enjoy good life conditions for longer [6]. Besides, the proportion of new infected patients being older 50 years is increasing. In fact, the mean age at the time of diagnosis is increasing in our cohort.

There are epidemiological differences associated with age. Like other surveys $[2,5,6,16]$, older patients in our cohort have a higher prevalence of sexual HIV transmission, a lower risk of transmission due to intravenous use, and a greater proportion of men. Remarkably, the number of older individuals whose risk behavior was unknown was much higher than the number of younger patients.

Unlike old patients, younger ones had higher prevalence of antibodies against Hepatitis $\mathrm{C}$ virus. This fact could be due to injected drugs are an important mode of Hepatitis $\mathrm{C}$ spread, besides infection drug user is the most prevalent HIV risk factor in younger individuals.

Even though there was more percentage of younger patients who received previous treatment at enrollment, most patients from both age groups received treatment during follow-up. In fact, there were no statistically significant differences between groups at any point of time considering number of patients receiving therapy. Besides, there was no difference in the use of antiretroviral therapy as described in other studies $[10,17]$. However, after HIVinfection diagnosis, older patients initiated HAART therapy sooner probably due to they are diagnosed later. Interestingly, some studies also described that younger and older patients present the same tolerance to therapy $[1,18]$. Thus, further studies should be necessary to analyze this fact in our region.

Both age groups show increasing CD4 cell counts and decreasing plasma viral load during follow-up. Like Grabar et al. observations [5], greatest responses were observed in the first six month. Virological response is

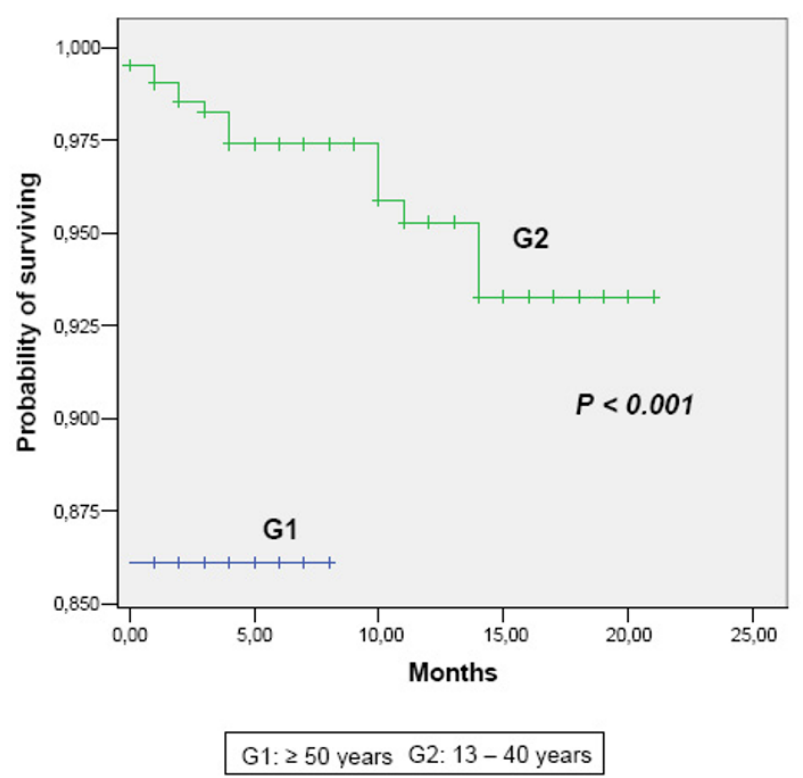

Figure 3

Cumulative survival rate, according to age group.

good in elderly group and they achieve lower viral load. Previous studies showed younger age is associated with lower virological response and virological rebounds $[5,12,19,20]$, probably due to older patients demonstrated better medication adherence. At least $90-95 \%$ of adherence is required to achieve optimal treatment [21]. Moreover, an inadequate adherence are also associated with the developed of drug-resistant HIV strains [22] Even though some studies show older age is associated to better adherence $[21,23,24]$, other ones observed that lower virological response in younger age persisted after adjusting for regimen adherence, antiretroviral therapy and disease stage $[12,20]$. Therefore, others variables could be implied. Adherence information was not surveyed in our database.

The age has been associated to deficiencies in the immune system, with a progressive depletion of lymphocytes $[7,17,25]$. Moreover, thymic volume, which decreases with age, is associated with recovery of CD4 T cells $[1,26]$. However, Virad et al. showed CD4 recovery in older patients [13]. Recent data suggest substantial output of CD4 cells can be maintained in advanced age, even with less thymic function. Thus, HAART therapy contributes to immune recovery in older patients, too [10]. At first clinic visit, CD4 cell counts were lower in our older patients. However, both age groups had favorable and parallel immune response. Elderly group did not achieve the same immune restoration, probably due to their lower baseline CD4 cell counts. 
Until the introduction of HAART, age was a strong predictor of disease progression and mortality risk [27]. Nevertheless, there are controversial results since 1996. Some studies show that older patients have poorer immune response $[7,8]$. In contrast, some surveys seem to demonstrate that virological and immune response in older HIVinfected people receiving HAART is similar to that of younger patients $[9,14,28,29]$. For instance, Perez et al. observed older patients have a great benefit associated with HAART, suggesting lower survival in older people was due to late diagnosis [6]. Tumbarello et al. have demonstrated that older patients under HAART therapy can achieve the same response, although they present a more severe HIV infection [10]. According to our results, it is felt that our analysis agrees with the last studies.

There was no significant difference with regard to AIDS criteria at the enrollment in our patients. Nevertheless, not only greater number of older patients developed AIDS, but also disease progression and mortality since HIV diagnosis were faster in older patients.

Previous data showed that elderly patients are diagnosed later $[30,31]]$. Taking into account good immunological and virological responses were observed in both groups, faster progression to AIDS and shorter survival in older patients may be due to delayed diagnosis and thus a smaller chance of having received antiretrovirals. In fact, there was lower proportion of elderly patients being on treatment at enrollment. Moreover, elderly patients had lower CD4 cell counts at enrollment and thus they did not achieve the same counts as younger patients at the end of follow-up. There is not a high HIV-infection suspicious in old patients' diagnosis because of: firstly, different epidemiological features associated to age; secondly, the fact that HIV-infection has been associating to younger age. Thus, many old people are unaware of their serostatus. In fact, in our cohort there were a high number of older HIVinfected patients whose risk behavior is unknown. Consequently, even though older patients' response to HAART is parallel to younger patients' response, their immune and virological data were worst at first clinic visit and thus their progression to AIDS was faster and their survival was shorter.

\section{Conclusion}

In conclusion, there are epidemiological differences related to age. Immunological and virological behaviors during follow-up are similar within both age groups. However, older patients have worse features at first clinic visit. Consequently, it is essential physicians know older HIV-infected patients features to consider the possibility of HIV infection in these patients with the aim of treatment would not be delayed.

\section{Competing interests}

MaMercedes Nogueras, Gemma Navarro, Esperança Antón, Montserrat Sala, Manel Cervantes, MaJosé Amengual: The authors declare that they have no competing interests.

Ferran Segura: He has participated in scientific meeting receiving financial support from pharmaceutical industry regarding antibiotics and antiretrovirals. However, none of them are concerning this study.

\section{Authors' contributions}

MMN carried out the analysis and interpretation of data, and the preparation and revision of manuscript.

GN participated in the study concept and design, and revision of manuscript.

EA participated in the acquisition of subjects and epidemiological and clinical data.

MS participated in the study concept, acquisition of subjects and epidemiological and clinical data.

MC participated in the study concept, acquisition of subjects and epidemiological and clinical data.

MJA participated in the acquisition of data from laboratory.

FS participated in the study concept and design, and revision of manuscript.

\section{Acknowledgements}

The authors would like to thank Ángeles Jaén, Jordi Casabona, and PISCIS group for their design and collaboration on database.

We thank Jordi Real Gatius and Eva Penelo Werner for advice on biostatistics. We also thank José Manuel Aisa Mancho for reviewing the English.

This study was supported by Fundación Barcelona SIDA 2002, FIPSE 20002002-05-22, and "Red Española de Investigación en Patología Infecciosa" REIPI.

\section{References}

I. Manfredi R: HIV infection and advanced age emerging epidemiological, clinical, and management issues. Ageing Res Rev 2004, 3:3 I-54.

2. Centers for Disease Control and Prevention: HIVIAIDS surveillance Volume 13. Issue 2 Atlanta, GA: Centers for Disease Control and Prevention; 200I.

3. HIVIAIDS Surveille in Europe. European Centre for the Epidemiological Monitoring of AIDS. Med-year report 2002, $n^{\circ} 67$.

4. Centro Nacional de Epidemiología: Vigilancia Epidemiológica del SIDA en España. REGISTRO NACIONAL DE CASOS DE SIDA ACTUALIZACIÓN A 3I DE DICIEMBRE DE 2004 Informe Semestral n I, Año 2005.

5. Grabar S, Kousignian I, Sobel A, Le Bras P, Gasnault J, Enel P, Jung C Mahamat A, Lang JM, Costagliola D: Immunologic and Clinical Response to Highly Active antiretroviral therapy over $\mathbf{5 0}$ years of age. Results from the French Hospital Database on HIV. AIDS 2004, 18:2029-2038. 
6. Perez JL, Moore RD: Greater effect of highly active antiretroviral therapy on survival in people aged $\geq \mathbf{5 0}$ years compared to younger people in an urban observational cohort. Clin Infect Dis 2003, 36:2/2-218.

7. Kaufmann G, Bloch M, Finlayson R, Zaunders J, Smith D, Cooper DA: The extent of HIV-I related immunodeficiency and age predict the long term CD4 T lymphocyte response to potent antiretroviral therapy. AIDS 2002, 16:359-367.

8. Goetz MB, Boscardin WJ, Wiley D, Alkasspooles S: Decreased recovery of CD4 lymphocytes in older HIV-infected patients beginning highly active antiretroviral therapy. AIDS 200I, I 5: 1576-1579.

9. Knobel H, Guelar A, Valldecillo G, Carmona A, Gonzalez A, LopezColomes JL, Saballs P, Gimeno JL, Diez A: Response to highly antiretroviral therapy in HIV-infected patients aged 60 years or older alter 24 months follow-up. AIDS 200I, I5:|59|-I593.

10. Tumbarello M, Rabagliati R, de Gaetano Donati K, Bertagnolio S, Montuori E, Tamburrini E, Tacconelli E, Cauda R: Older age does not influence CD4 cell recovery in HIV-I infected patients receiving highly active anti retroviral therapy. $B M C$ Infect Dis 2004, 4:46.

II. Jaén A, Casabona J, Esteve A, Miró JM, Tural C, Ferrer E, Riera M, Segura F, Force L, Sued O, Vilaró J, Masabeu A, García I, Dorca E, Altès J, Navarro G, Podzamczer D, Villalonga C, Clotet B, Gatell JM, Grupo de estudio PISCIS: [Clinical-epidemiological characteristics and antiretroviral treatment trends in a cohort of HIV infected patients. The PISCIS Project]. Med Clin (Barc) 2005, 124:525-53|.

12. Goodkin K, Shapshak P, Asthana D, Zheng W, Concha M, Wilkie FL Molina R, Lee D, Suarez $P$, Symes $S$, Khamis I: Older age and plasma viral load in HIV-I infection. AIDS 2004, I 8(Suppl I):87-98.

13. Viard JP, Mocroft A, Chiesi A, Kirk O, Roge B, Panos G, Vetter N Bruun JN, Johnson M, Lundgren JD, EuroSIDA Study Group: Influence of age on CD4 cell recovery in human immunodeficiency virus-infected patients receiving highly active antiretroviral therapy: evidence from the EuroSIDA study. Infect Dis 200I, 1 83: I 290-1294.

14. Tumbarello M, Rabagliati R, De Gaetano Donati K, Bertagnolio S, Tamburrini E, Tacconelli E, Cauda R: Older HIV-positive patients in the era of highly active antiretroviral therapy: changing of a scenario. AIDS 2003, 17:128-131.

15. Uphold CR, Maruenda J, Yarandi HN, Sleasman JW, Bender BS: HIV and older adults clinical outcomes in the era of HAART. J Gerontol Nurs 2004, 30:16-24.

16. Suarez-Lozano I, Fajardo JM, Garrido M, Roca B, Garcia-Alcalde ML, Geijo P, Selma D, Lozano F, Teira R, Viciana P, Perez-Cortes $S$, Domingo P, Menchero A, Galindo MJ, Cosin J, Ribera E, Arribas JR, Lacalle JR: Epidemiological trends of HIV infection in Spain: preventive plans have to be oriented to new target population (Spanish VACH Cohort). AIDS 2002, 16:2496-2499.

17. Butt AA, Dascomb KK, Desalvo KB, Bazzano L, Kissinger PJ, Szerlip HM: Human Immunodeficiency virus infection in elderly patients. South Med J 200I, 94:397-400.

18. Adeyemi D, Bradi S, Max B, Chinomona N, Barrer D: HIV infection in older patients. Clin Infect Dis 2003, 36: 1347

19. Grabar S, Pradier C, Le Corfec E, Lancar R, Allavena C, Bentata M, Berlureau P, Dupont C, Fabbro-Peray P, Poizot-Martin I, Costagliola $D$ : Factors associated with clinical and virological failure in patients receiving a triple therapy including a protease inhibitor. AIDS 2000, |4:|4|-149.

20. Le Moing V, Chene G, Carrieri MP, Alioum A, Brun-Vezinet F, Piroth L, Cassuto JP, Moatti JP, Raffi F, Leport C, Aproco Study Group: Predictors of virological rebound in HIV-I-infected patients initiating a protease inhibitor-containing regimen. AIDS 2002, 16:21-29.

21. Paterson DL, Swindells S, Mohr J, Brester M, Vergis EN, Squier C Wagener MM, Singh N: Adherence to protease inhibitor therapy and outcomes in patients with HIV infection. Ann Intern Med 2000, 133:21-30.

22. Gifford AL, Bormann JE, Shively MJ, Wright BC, Richman DD, Bozzette SA: Predictors of self-reported adherence and plasma HIV concentrations in patients on multidrug antiretroviral regimens. J Acquir Immune Defic Syndr 2000, 23:386-395.

23. Wutoh AK, Brown CM, Kumoji EK, Daftary MS, Jones T, Barnes NA Powell NJ: Antiretroviral adherence and use of alternative therapies among older HIV-infected adults. I Natl Med Assoc 200I, 93:243-250

24. Hinkin CH, Hardy DJ, Mason KI, Castellon SA, Durvasula RS, Lam MN, Stefaniak M: Medication adherence in HIV-infected adults: effect of patient age, cognitive status, and substance abuse. AIDS 2004, I 8(Suppl I): 19-25.

25. Fagnoni FF, Vescovini R, Passeri G, Bologna G, Pedrazzoni M, Lavagetto G, Casti A, Franceschi C, Passeri M, Sansoni P: Shortage of circulating naive CD8+ $T$ cells provides new insights on immunodeficiency in aging. Blood 2000, 95:2860-2868.

26. Ruiz-Mateos E, Rubio A, Vallejo A, De la Rosa R, Sanchez-Quijano A, Lissen $E$, Leal $M$ : Thymic volume is associated independently with the magnitude of short- and long-term repopulation of CD4+ $T$ cells in HIV-infected adults after highly active antiretroviral therapy (HAART). Clin Exp Immunol 2004, 136:50|-506.

27. Darby SC, Ewart DW, Giangrande PLF, Spooner RJD: Importance of age at infection with HIV-I for survival development of AIDS in UK haemophilia population. UK Haemophilia Centre Directors' Organisation. The Lancet 1996, 347:1573-I579.

28. Wellons M, Sanders L, Edwards L, Bartlett J, Helad A, Schmader K: HIV infection: treatment outcomes in older and younger adults. I Am Geriatr Soc 2002, 50:603-607.

29. Grimes RM, Otiniano ME, Rodriguez-Barradas MC, Lai D: Clinical experience with human immunodeficiency virus-infected older patients in the era of effective antiretroviral therapy. Clin Infect Dis 2002, 34:1530-1533.

30. Gordon S, Thompson S: The changing epidemiology of human immunodeficiency virus infection in older patients. J Am Geriatr Soc 1995, 43:7-9.

31. Zelenetz P, Epstein M: HIV in the elderly. AIDS patient Care ST $1998,4: 255-262$

\section{Pre-publication history}

The pre-publication history for this paper can be accessed here:

http://www.biomedcentral.com/1471-2334/6/159/pre pub
Publish with Bio Med Central and every scientist can read your work free of charge

"BioMed Central will be the most significant development for disseminating the results of biomedical research in our lifetime. "

Sir Paul Nurse, Cancer Research UK

Your research papers will be:

- available free of charge to the entire biomedical community

- peer reviewed and published immediately upon acceptance

- cited in PubMed and archived on PubMed Central

- yours - you keep the copyright
BioMedcentral 